DOI: http://dx.doi.org/10.18764/2358-4319.v13n2p250-269

\title{
A Práxis Inclusiva dos Núcleos de Atendimento a Pessoas com Necessidades Específicas e sua Relevância na Educação Profissional e Tecnológica
}

\author{
Fernanda Souza da Silva ${ }^{1}$ \\ Álvaro Itaúna Schalcher Pereira ${ }^{2}$ \\ Francisco Adelton Alves Ribeiro 3
}

\section{RESUMO}

O presente artigo tem por objeto abordar o tema da práxis da inclusão e a relação com os Núcleos de Atendimento a Pessoas com Necessidades Específicas - NAPNEs - no âmbito dos Institutos Federais de Educação, Ciência e Tecnologia, enfatizando a importância dos espaços formais que promovem e executam as legislações e diretrizes de inclusão por meio de ações e práticas de Atendimento Educacional Especializado, como agentes que facilitam a entrada, permanência e saída com êxito do discente com deficiência nos processos de ensino e aprendizagem. O método utilizado foi a pesquisa bibliográfica, abordando alguns conceitos que embasam a importância da inclusão além da teoria e do discurso para a educação e o mundo do trabalho, e documental, demonstrando as práticas inclusivas estabelecidas nas legislações e informações sobre a criação e finalidade dos NAPNEs. Os mesmos atuam na inclusão articulada com a Educação Profissional e Tecnológica, sendo agentes de transformação na vida dos discentes com os demais tipos de deficiências, possibilitando uma vida mais autônoma, independente e proporcionando melhorias no processo formativo de aquisição de conhecimentos. Com o desafio de aplicar as legislações vigentes de inclusão na prática, os NAPNEs podem encontrar na práxis da inclusão a ação transformadora e libertadora, que cria e modifica realidades até então determinadas por sistemas excludentes, colaborando na

1 Mestre em Educação Profissional e Tecnológica pelo Instituto Federal do Maranhão (ProfEPT). E-mail: fernanda_s13@hotmail.com

2 Doutor em Engenharia e Ciência de Alimentos, Docente do Instituto Federal de Educação, Ciência e Tecnologia do Maranhão, Programa de Programa de Pós-Graduação em Educação Profissional e Tecnológica (ProfEPT).E-mail: alvaro.pereira@ifma.edu.br

3 Doutor em Biotecnologia. Professor do Instituto Federal de Educação, Ciência e Tecnologia do Maranhão, Programa de Programa de Pós-Graduação em Educação Profissional e Tecnológica (ProfEPT).E-mail: adelton@ifma.edu.br 
construção de sociedades abertas à diversidadee construindo, dentro do espaço formal de aprendizagem, a prática libertadora da condição de oprimido, para uma formação humana educacional e profissional mais completa.

Palavras-chave: Educação Inclusiva. Formação Humana.Institutos Federais. Práticas Inclusivas.

\section{The Inclusive Praxis of the Centers of Attention to People with Specific Needs and their Relevance in Professional and Technological Education}

\section{ABSTRACT}

The purpose of this article is to address the theme of the inclusion praxis and the relationship with the Centers of Assistance to People with Specific Needs (NAPNEs) within the Federal Institutes of Education, Science and Technology, emphasizing the importance of the formal spaces that promote and implement the legislation and guidelines for inclusion through actions and practices of Specialized Educational Assistance, as agents that facilitate the successful entry, stay and exit of the student with disabilities in the teaching and learning processes. The method used was the bibliographical research, addressing some concepts that support the importance of inclusion besides theory and discourse for education and the world of work, and documentary, demonstrating the inclusive practices established in the legislations and information on the creation and purpose of the NAPNEs. They act in the articulated inclusion with the Professional and Technological Education, being agents of transformation in the life of the students with the other types of deficiencies, enabling a more autonomous life, independent and providing improvements in the formative process of knowledge acquisition. With the challenge of applying current legislation for inclusion in practice, NAPNEs can find in the praxis of inclusion transformative and liberating action that creates and modifies realities hitherto determined by exclusionary systems, collaborating in the construction of societies open to diversity and building, within the formal learning space, the liberating practice of the condition of the oppressed, for a more complete human educational and professional formation.

Keywords: Inclusive Education. Human Formation. Federal Institutes. Inclusive Practices. 


\section{La Praxis Inclusiva de los Núcleos de Atención a Personas con Necesidades Específicas y su Relevancia en la Educación Profesional y Tecnológica}

\section{RESUMEN}

El presente artículo tiene por objetivo abordar el tema de la praxis de la inclusión y la relación con los Núcleos de Atención a Personas con Necesidades Específicas - NAPNEs - en el ámbito de los Institutos Federales de Educación, Ciencia y Tecnología, enfatizando la importancia de los espacios formales que promueven y ejecutan las legislaciones y directrices de inclusión a través de acciones y prácticas de Atención Educacional Especializado, como agentes que facilitan la entrada, la permanencia y la salida con éxito del discente con deficiencia en los procesos de enseñanza y aprendizaje. El método utilizado fue la investigación bibliográfica, abordando algunos conceptos que fundamentan la importancia de la inclusión además de la teoría y del discurso para a educación y el mundo laboral, y documental, demostrando las prácticas inclusivas establecidas en las legislaciones e informaciones sobre la creación y finalidad de los NAPNEs. Estos actúan en la inclusión articulada con la Educación Profesional y Tecnológica, siendo agentes de transformación en la vida de los discentes con diversos tipos de deficiencia, posibilitando una vida más autónoma, independiente y proporcionando mejorías en el proceso formativo de adquisición de conocimientos. Con el desafío de aplicar las legislaciones vigentes de inclusión en la práctica, los NAPNEs pueden encontrar en la praxis de la inclusión la acción transformadora y libertadora, que crea y modifica realidades hasta entonces determinadas por sistemas excluyentes, colaborando con la construcción de sociedades abiertas a la diversidad y construyendo dentro del espacio formal de aprendizaje la práctica libertadora de la condición de oprimido, para una formación humana educacional y profesional más completa.

Palabras clave: Educación Inclusiva. Formación Humana. Institutos Federales. Prácticas Inclusivas.

\section{Introdução}

Este artigo faz parte das reflexões da dissertação de mestrado intitulada "A inclusão escolar de discentes com deficiência física: con- 
tribuição para uma práxis inclusiva no instituto federal do maranhão a partir do desenvolvimento de um aplicativo educacional", que analisa a práxis da inclusão na Educação Profissional e Tecnológica - EPT - com o objetivo de desenvolver um Aplicativo Educacional com informações sobre as práticas inclusivas do espaço formal de aprendizagem lócus da pesquisa para pessoas com deficiência física.

A história da educação das pessoas com deficiência no Brasil passa por momentos de exclusão que marcaram a trajetória educacional vivenciada por essas pessoas, caracterizando sua inserção tardia na educação e no mundo do trabalho, e por muitas vezes precária. Jannuzzi (2004) aponta que as políticas para a educação da pessoa com deficiência só avançaram à medida dos interesses das classes dominantes, acompanhando as mudanças sociais e, principalmente, as mudanças econômicas que ocorriam no país e no mundo.

Nesse movimento, à inserção da pessoa com deficiência no sistema regular e público de educação passa por diferentes fases e conceitos. As mesmas dividem-se em fase da exclusão, quando as pessoas com deficiência não tinham acesso a ambientes de educação e de trabalho comuns aos que não tinham deficiência; fase da segregação, com a existência de espaços de educação separados dos demais espaços em comum de aprendizagem; a fase da integração, caracterizada pela inserção das pessoas com deficiência nos espaços comuns de aprendizagem para que elas se adaptassem aos mesmos, contudo sem apoio especializado ( se não conseguissem se adaptar, frequentariam espaços especializados segregados); e, por fim, o atual conceito, o da inclusão, na perspectiva da adaptação da sociedade para a pessoa com deficiência poder ter sua vida com autonomia e independência garantida (SASSAKI, 1999), já que as sociedades constroem-se e configuram-se em elementos excludentes para aqueles que são considerados "diferentes" ou "improdutivos".

O movimento mundial pela educação inclusiva é uma ação política, cultural, social e pedagógica, desencadeada em defesa do direito de todos os estudantes de estarem juntos, aprendendo e participando, sem nenhum tipo de discriminação. A educação inclusiva constitui um paradigma educacional fundamentado na concepção de direitos humanos, que conjuga igualdade e diferença como valores indissociáveis, e que avança em relação à ideia de equidade formal ao contextualizar as circunstâncias históricas da produção da exclusão dentro e fora da escola (BRASIL, 2008a, não paginado). 
Nos espaços formais de aprendizagem, essa adaptação é disciplinada pelas políticas públicas que visam à inclusão no sistema educacional, determinando o apoio educacional especializado para executar as práticas de inclusão no ambiente interno da instituição. Assim, o Atendimento Educacional Especializado - AEE - passa as ser instrumento para a práxis da inclusão, consistindo na transformação da realidade (VAZQUEZ, 2002) excludente em que pode consistir uma educação não acessível à pessoa com deficiência.

Nos Institutos Federais de Educação, Ciência e Tecnologia IFs, a prática das ações se dá por meio dos Núcleos de Atendimento a Pessoas com Necessidades Específicas - NAPNEs, que possuem diferentes formas de garantir o AEE para os discentes com deficiência que ali ingressam e de acordo com cada deficiência, entendendo que a educação inclusiva articulada com a EPT pode ser fator relevante para a qualidade do aprendizado e construção do ser autônomo e independente, com qualificação profissional e social para ingressar no mundo do trabalho.

Assim, o primeiro momento desta discussão irá trazer o conceito da práxis como ação transformadora e como ação libertadora de realidades excludentes, em que, apenas com a prática refletida, é que se pode efetivar a inclusão, em um processo que deve considerar os discentes para que sejam os protagonistas de suas histórias, libertando-se e reconhecendo-se como sujeitos autônomos e independentes.

No segundo momento, são abordadas algumas das legislações e diretrizes que impulsionaram a inclusão na educação e a preparação para o mundo do trabalho, descrevendo a criação do movimento da inclusão na EPT, por meio da Ação TEC NEP, que teve como um dos resultados a implantação dos NAPNEs nos Instituto Federais - IFs, como Núcleos de apoio e execução das práticas de inclusão para pessoas com deficiência.

No último momento, serão abordadas algumas práticas de inclusão que as legislações propõem como diretrizes para o AEE obrigatório nos espaços formais de aprendizagem, em que os NAPNEs encontram o desafio de aplicá-las de acordo com suas possibilidades e estrutura, para que a inclusão passe da teoria para uma prática refletida, de acordo com a realidade do local e de cada discente, a fim de possibilitar uma formação humana educacional e profissional, com autonomia e independência. 
Por fim, o texto traz as considerações finais, ressaltando a importância dos NAPNEs para a ação da práxis inclusiva em busca de uma sociedade mais justa, igualitária e aberta à diversidade.

\section{A práxis da inclusão}

No conceito mais atual de inclusão, como a "modificação da sociedade como pré-requisito para a pessoa com necessidades especiais buscar seu desenvolvimento e exercer a cidadania" (SASSAKI, 1999, p. 43), trabalhando nas diretrizes de adequação da sociedade à pessoa com deficiência, a práxis inclusiva torna-se instrumento fundamental para a execução das políticas que visem à inclusão, podendo ser agente de ação transformadora da realidade que discentes com deficiência se encontram.

Nesse sentido, a reflexão sobre os meios de execução que efetivem as práticas de inclusão nos espaços de aprendizagem para além da teoria e de atendimento a leis, trazem a concepção de escolas inclusivas, que mais que colocar o discente com deficiência em seu ambiente, deve promover ações de AEE para uma permanência de qualidade e uma saída do sistema de ensino com aprendizagem e autonomia nas suas atividades, como afirma Mantoan (2003, p. 16) "As escolas inclusivas propõem um modo de organização do sistema educacional que considera as necessidades de todos os alunos e que é estruturado em função dessas necessidades", sendo necessárias ações que visem à articulação de legislações, programas e atitudes em prol da inclusão para sua concretização.

A práxis é entendida como uma atividade prática humana, a um só tempo subjetivo e objetivo, ideal e real, espiritual e material, que desemboca na transformação prática, efetiva, do mundo do homem; portanto, não se trata de apenas transformar sua consciência, mas também as relações e instituições sociais que condicionam sua consciência, sua subjetividade (VÁZQUEZ, 2002, p. 70, tradução nossa).

A prática da inclusão, assim, torna-se fundamental para a transformação da realidade excludente em que o ensino escolar foi pautado ao longo de sua história. A prática pensada e aplicada, refletida sobre seus aspectos teóricos, ressignifica a intervenção nos ambientes educacionais, tratando-se de proporcio- 
nar experiências, vivências, conhecimentos e sociabilidade a partir do até então status quo, já que a ação humana transformadora pressupõe negar uma realidade para transformá-la, e isso significa colocar os discentes com deficiência como protagonistas de sua história e trajetória escolar com condições para promover sua autonomia, como agentes de sua história, que conhecem os seus direitos e que possuam voz, não estando ali apenas para escutar, mas para se fazer presente e contribuindo para a formação de uma sociedade que aceita e respeita a diversidade (FREIRE, 1985).

Aceitar e respeitar a diferença são uma dessas virtudes sem o que a escuta não se pode dar. Se discrimino o menino ou a menina pobre, a menina ou o menino negro, o menino índio, a menina rica; se discrimino a mulher, a camponesa, a operária, não posso evidentemente escutá-las e se não as escuto, não posso falar com eles, mas a eles, de cima para baixo. Sobretudo, me proíbo entendê-los. Se me sinto superior ao diferente, não importa quem seja, recuso-me escutá-lo ou escutá-la. O diferente não é o outro a merecer respeito, é um isto ou aquilo, destratável ou desprezível (FREIRE, 1996, p.29).

Ao analisar a inclusão de pessoas com deficiência sob a perspectiva de Paulo Freire, verifica-se a aproximação desse processo com os estudos e obras do autor e a práxis. Por mais que os ambientes formais de aprendizagem estejam, por muitas vezes, condicionados a uma educação determinada pelo sistema produtivo, Freire (2002) aponta os homens como sujeitos da práxis, que não apenas observam o mundo, mas agem sobre ele, rompendo o ciclo excludente e o transformando, sendo essencial a ação, e no caso das práticas de inclusão, refletida em suas bases legislativas, teóricas, experimentais e de vivências para que possam mudar realidades e contribuírem na construção do sujeito autônomo e independente.

Ao propor uma educação dialógica, baseada em discussões, diálogos e debates na tentativa de transformar realidades, Freire concebe o espaço formal de aprendizagem como local de mudanças e de libertação da condição de seres excluídos, trazendo a práxis libertadora para o enfrentamento de situações que discentes com deficiência compreendem a partir do reconhecimento e entendimento de suas realidades, libertando-os da condição de oprimidos, excluídos (FREIRE, 1996, 2001, 2002, 2011). 
[...] é sempre processo, e sempre devir, passa pela ruptura das amarras reais, concretas, de ordem econômica, política, social, ideológica etc., que nos estão condenando à desumanização. O sonho é assim uma exigência ou uma condição que se vem fazendo permanente na história que fazemos e que nos faz e re-faz (FREIRE, 2001, p. 99).

Dessa forma, a práxis de inclusão torna-se instrumento para a formação humana dos discentes com deficiência, colocando a ação refletida como apoio na melhoria da qualidade do ensino e aprendizagem, da sociabilidade, da autonomia, da independência e da cidadania de sujeitos que se empossam e participam do espaço escolar e que, em uma educação formada por todos, transformam a realidade e libertam-se das amarras do domínio.

Em espaços públicos de aprendizagem, para a implantação de ações de inclusão, faz-se necessária a organização de programas e diretrizes de ações afirmativas no sistema educacional que incentivem e obriguem a execução das mesmas, com o objetivo também de compensar um passado de exclusão que marcam a história da educação da pessoa com deficiência.

Segundo Queiroz (2016, p. 188), as ações afirmativas reconhecem que "grupos foram historicamente tratados de forma injusta e, portanto, devem ser 'compensados' pelas perdas sofridas", de maneira que a igualdade de condições seja promovida respeitando as necessidades de cada um.

Dessa forma se organiza a Rede Federal de Educação Profissional, Científica e Tecnológica - RFEPCT, com a criação do Programa TEC NEP - Educação, Tecnologia e Profissionalização para Pessoas com Necessidades Específicas e a implantação dos Núcleos de Atendimento a Pessoas com Necessidades Específicas - NAPNEs - em cada campus dos Institutos Federais de Educação, Ciência e Tecnologia pelo Brasil, com o objetivo de promover a inclusão articulada com a EPT. Para isso, são desenvolvidas ações internas nos Campus através dos NAPNEs para meIhor incluir os discentes com deficiência, com AEE e outras atuações que colaborem nesse sentido, aplicadas na prática do cotidiano educacional, indo além da inclusão em sua face teórica.

[...] a teoria em si não transforma o mundo. Pode contribuir para sua transformação, mas para isto tem que sair de si mesma. Entre a teoria e a atividade prática 
transformadora se insere um trabalho de educação das consciências, de organização de meios materiais e planos concretos de ação: tudo isso como passagem indispensável para desenvolver ações reais e efetivas. Nesse sentido, uma teoria é prática na medida em que materializa, através de uma série de mediações, o que antes só existia idealmente [...] (VASQUEZ, 1977, p. 206).

Apesar dos avanços nas legislações para pessoas com deficiência na educação e no trabalho, a participação social e o exercício da cidadania como sujeitos de deveres e de direitos ainda são mitigados quando a inclusão não é realizada, devendo ser elementos postos e ressaltados como parte dos projetos, programas e ações de inclusão no interior dos ambientes em que estão sendo inseridos. A inclusão, mais que a presença física de uma pessoa com deficiência, pode ser fator de independência e autonomia como preparação para permanência no sistema educacional e como preparação para uma formação de qualidade para o mundo do trabalho.

Segundo Sassaki (1999), autonomia significa possibilidades de alcançarem seus objetos em qualquer ambiente com dignidade, seja na locomoção ou na sua sociabilidade, e a independência o poder de tomar suas próprias decisões sem a interferência de outras pessoas, e ambas podem ser desenvolvidas no processo de desenvolvimento da pessoa com deficiência. Nesse processo, os espaços formais de aprendizagem possuem papel fundamental com práxis da inclusão numa perspectiva de formação humana.

Nesse sentido, a EPT não deve ser vista como modalidade de ensino voltada apenas para o mercado de trabalho, com o aprendizado de técnicas, mas sim, no seu poder articulador de construção da cidadania ativa de discentes tanto no trabalho quanto na sociedade (CARNEIRO, 2011), considerando sua independência, autonomia e adaptação ao mundo produtivo. Incluir em uma formação para o mundo do trabalho, contribui para a formação humana e integral dos indivíduos, capazes de serem protagonistas de suas próprias histórias e atuarem na profissão que escolheram com reconhecimento de sua profissionalização, sabendo de seus direitos e deveres enquanto cidadãos.

De acordo com o documento Declaração de Salamanca, resultado da Conferência Mundial sobre Necessidades Educacionais Especiais, na cidade de Salamanca, na Espanha, em 1994, a transição da escola para 
o trabalho com formação de qualidade, para participarem ativamente do mundo do trabalho e possuir vida econômica ativa, é um direito das pessoas com deficiência, cabendo às instituições de ensino prepará-los para tal por meio de ações e práticas que facilitem a inclusão da pessoa com deficiência.

$\S 55$. Os jovens com necessidades educacionais especiais devem receber ajuda para fazer uma eficaz transição da escola para a vida adulta produtiva. As escolas devem ajudá-los a se tornarem economicamente ativos e prover-lhes as habilidades necessárias no dia-a-dia, oferecendo treinamento em habilidades que respondam às demandas sociais e de comunicação e às expectativas da vida adulta. Isto requer tecnologias apropriadas de treinamento, incluindo experiência direta em situações de vida real fora da escola. Os currículos para os alunos com necessidades educacionais especiais em classes mais adiantadas devem incluir programas transicionais específicos, apoio para ingressarem no ensino superior sempre que possível e subsequente treinamento profissional que os prepare para atuarem como membros contribuintes independentes em suas comunidades após terminarem estudos. [...] (UNESCO, 1998a, p. 34).

Assim, as práticas em favor da acessibilidade e atuação de núcleos especializados no AEE tornam-se fundamentais para a promoção da inclusão nos espaços formais de aprendizagem, seguindo ações que contribuam para melhoria na trajetória educacional do discente, promovendo também a sensibilização e atitude de outros membros da comunidade escolar, como ocorre nos IFs, por meio dos NAPNEs, no atendimento a pessoa com deficiência, que visando uma EPT inclusiva, de formação humana educacional e profissional.

\section{A educação profissional e tecnológica}

A inclusão das pessoas com deficiência nos espaços formais de aprendizagem passa pelos processos político, econômico e social da sociedade brasileira que condicionam a entrada e participação de discentes com Necessidades Educacionais Específicas - NEE, conforme os contextos determinados, principalmente, pela formação de seres produtivos para a demanda do capital. 
Januzzi (2004), ao abordar a história da inclusão, coloca que até 1973 não se falava da educação e profissionalização da pessoa com deficiência como fator de desenvolvimento econômico, mas sim, em uma perspectiva assistencialista, apesar de haver oficinas separadas do ensino comum, que os preparavam para ofícios, a fim de que, inseridos em algum trabalho, tivessem o mínimo para se manterem.

A partir da Constituição Federal de 1988, os direitos individuais passam a ser estabelecidos em um processo democrático, trazendo a educação como Direito Social para todos e indo ao encontro de movimentos a favor da inclusão que marcaram as diretrizes e a concepção de adaptação da sociedade, que originaram documentos que enfatizavam a preocupação da inclusão da pessoa com deficiência na educação para uma vida digna, e provocavam a sociedade para a ação transformadora da realidade excludente, como a Declaração Mundial de Educação para Todos, ocorrida em Jontiem em 1990, na Tailândia e a Declaração de Salamanca, em 1994, em Salamanca, Espanha.

Em 1996, é criada a Lei de Diretrizes e Bases da Educação Brasileira - LDB, Lei no 9.394 de 20 de dezembro de 1996, trazendo em seu artigo 4\%, inciso III, a garantia de "atendimento educacional especializado gratuito aos educandos com deficiência, transtornos globais do desenvolvimento e altas habilidades ou superdotação, transversal a todos os níveis, etapas e modalidades, preferencialmente na rede regular de ensino" (BRASIL, 1996), o que demonstra a preocupação e as diretrizes das bases educacionais no sentido da inclusão, adaptando os espaços formais de aprendizagem e preparando o apoio e auxílio necessário. A LDB/96 ainda traz a educação inclusiva para o trabalho, como suporte educacional para a integração no mundo do trabalho, proporcionando condições para que a pessoa com deficiência possa ter uma vida mais independente e exercer os seus direitos sociais.

Nos anos 2000, na RFEPCT cria o Programa TEC NEP, pelas até então Secretaria de Educação Média e Tecnológica - SEMTEC e Secretaria de Educação Especial - SEESP, do Ministério da Educação, para, através de práticas de inclusão, atender as pessoas com deficiência, possibilitando uma formação mais completa, humana e visando a "inserção e permanência de pessoas com necessidades especiais no mercado de trabalho, através da abertura de espaços nas escolas profissionalizantes da rede federal" (ANJOS, 2006, p. 42). A inclusão passa assim a ser instrumento de contribuição para a formação profissional e o direito a estar 
dentro do mundo do trabalho como profissional capacitado da área que escolheu.

De acordo com Nascimento e Faria (2013), o Programa desenvolveu-se em quatro momentos, sendo a Mobilização e sensibilização, de 2000 a 2003, para apresentação do Programa TEC NEP em evento com participantes representantes das Instituições da Rede; a Consolidação dos Grupos Gestores, dos Núcleos de Atendimentos às Pessoas com Necessidades Específicas - NAPNEs e a estratégia de implantação da Ação TEC NEP, de 2003 a 2006, em que constitui 5 pólos Gestores Regionais para descentralizar as ações de oferta de EPT às pessoas com NEE. Nesse momento, foi decidida a criação dos NAPNEs no âmbito dos IFs e a estratégia de implementação do processo de preparar as Instituições para receber o discente com NEE e atendê-lo para melhor proporcionar a articulação entre a inclusão e a EPT, a formação humana e o mundo do trabalho.

Ainda de acordo com os autores, o terceiro momento, 2007 a 2009, é o da Formação de Recursos Humanos, uso e desenvolvimento de tecnologia assistiva, com cursos de formação de recursos humanos especializado para atuarem no atendimento aos discentes com NEE e pesquisas sobre novas TAs para melhor incluir o discente. Quanto ao quarto momento, enfatizam que "Não houve tempo para a implementação do Momento 4, que seria a instrumentalização dos NAPNEs (com recursos multifuncionais e formação de RH) para um melhor atendimento. A SETEC extinguiu a Coordenação de Ações Inclusivas em junho de 2011" (NASCIMENTO; FARIA, 2013, p. 22). Destaca-se que em 25 de fevereiro de 2010, a Secretaria de Educação Profissional e Tecnológica - SETEC, emitiu a Portaria $n^{\circ} 29$, com o objetivo de disciplinar a forma de operacionalizar o Programa TEC NEP, o mesmo passou a se chamar Ação Educação, Tecnologia e Profissionalização para pessoas com Necessidades Educacionais - TEC NEP (BRASIL, 2010).

Nessa conjuntura, os NAPNEs se estruturam e se fortalecem como espaço de práticas e serviços de apoio aos discentes com NEE. Os NAPNEs têm o objetivo de auxiliar os discentes para uma permanência com uma formação digna e de qualidade e saída com êxito, preparados para continuar estudando no Ensino Superior e/ou estar incluso no mundo do trabalho por sua capacitação profissional. Os núcleos são uma ação conjunta entre a Instituição, a comunidade e o discente, para a eliminação ou minimização de barreiras que possam vir a prejudicar a qualidade de vida escolar do discente. 
É o setor da instituição que articula pessoas e instituições desenvolvendo ações de implementação do Programa TEC NEP no âmbito interno, tendo como finalidade o desenvolvimento de projetos e ações que promovam a quebra das barreiras arquitetônicas, educacionais e atitudinais, disponibilizando serviços e recursos próprios para esse atendimento (CUNHA, 2011, p. 78).

Os NAPNEs possuem recursos matérias e humanos conforme a estrutura de cada Campus em que é criado, e suas práticas de AEE são executadas com o objetivo de contribuir para o ensino e aprendizagem do discente, seguindo as legislações de inclusão por meio de equipe especializada, compreendendo que "acessibilidade, formação de recursos humanos e adequação de material didático-pedagógico, se forem atendidas estas condições, facilitará o ingresso e permanência das pessoas com necessidades específicas na Rede Federal de EPT" (NASCIMENTO et al, 2011, p. 08), trazendo a relevância de espaço que reflitam a inclusão com uma práxis transformadora de espaços que podem excluir caso não haja intervenção. Na composição dos NAPNEs, a designação do Coordenador ou Coordenadora se dá por Portaria emitida pelo Reitor ou Reitora, e os demais profissionais seguem as diretrizes de cada IFs.

\section{NAPNEs: transformando e libertando}

A partir da perspectiva inclusiva, para atender os discentes com deficiência, o AEE executado por profissionais especializados na área da educação especial, é instrumento fundamental para promover a inclusão, com acessibilidade e adaptações de acordo com a especificidade provocada pela deficiência, sendo instrumento de ação transformadora de ambientes e metodologias excludentes.

O atendimento educacional especializado tem como função identificar, elaborar e organizar recursos pedagógicos e de acessibilidade que eliminem as barreiras para a plena participação dos alunos, considerando as suas necessidades específicas. As atividades desenvolvidas no atendimento educacional especializado diferenciam-se daquelas realizadas na sala de aula comum, não sendo substitutivas à escolarização. Esse atendimento complementa e/ou suplementa a formação dos alunos com vistas à autonomia e independência na escola e fora dela (BRASIL, 2008b, p. 15). 
Regulamentado pelo Decreto $n^{\circ} 7.611$, de 17 de novembro de 2011, o AEE, se dá através de profissionais especializados no próprio ambiente de ensino, sendo, para as pessoas com deficiência, complementar à formação "[...] como apoio permanente e limitado no tempo e na frequência dos estudantes às salas de recursos multifuncionais" (BRASIL, 2011, não paginado). Ainda segundo o decreto, articulado com outras políticas públicas, o AEE deve integrar a família, os estudantes e o projeto pedagógico da escola, tendo como objetivos, conforme o Artigo 3:

I - prover condições de acesso, participação e aprendizagem no ensino regular e garantir serviços de apoio especializados de acordo com as necessidades individuais dos estudantes;

II - garantir a transversalidade das ações da educação especial no ensino regular;

III - fomentar o desenvolvimento de recursos didáticos e pedagógicos que eliminem as barreiras no processo de ensino e aprendizagem; e

IV - assegurar condições para a continuidade de estudos nos demais níveis, etapas e modalidades de ensino (BRASIL, 2011, não paginado).

A LDB de 1996, que estabelece as diretrizes e bases da educação nacional, também aborda a inclusão a partir da educação especial com AEE para as pessoas com deficiência, além daquelas enquadradas com transtornos globais do desenvolvimento e altas habilidades ou superdotação, ressaltando, nos Incisos do Artigo 59, a adaptação de currículos, metodologias e recursos, a formação de professores especializados, o acesso igualitário a programas sociais, e a educação especial voltada para o trabalho, para integração em sociedade e agindo com articulação com órgãos afins para seu ingresso no mundo do trabalho (BRASIL, 1996).

A Lei no 13.146, de 6 de julho de 2015, que Institui a Lei Brasileira de Inclusão da Pessoa com Deficiência (Estatuto da Pessoa com Deficiência), traz em seu Capítulo IV, Do Direito à Educação, dispositivos sobre a obrigatoriedade do acesso de pessoas com deficiência na rede regular de ensino em todas as modalidades, colocando o AEE como suporte para a prática de inclusão nos espaços formais de aprendizagem.

Portanto, no rol de Incisos do Artigo 28 da referida Lei, pode-se destacar a institucionalização do AEE nos projetos pedagógicos de cada instituição; a oferta da educação também em Libras, de forma bilíngue 
com a língua portuguesa, com a disponibilização de Intérpretes de Libras; a preocupação e implantação de medidas individuais e coletivas para a melhor adaptação da pessoa com deficiência; pesquisas para desenvolver métodos e técnicas de aperfeiçoamento do AEE; o uso de equipamentos e tecnologias assistivas; a utilização de Sistema Braille; formação continuada para docentes e o apoio de profissionais especializados na área da educação especial; e acessibilidade em todos os espaços físicos e sociais (BRASIL, 2015). Tais práticas são em função do desenvolvimento das potencialidades da pessoa com deficiência, e o exercício da sua cidadania com autonomia e independência.

Os NAPNEs possuem organização e estrutura de acordo com Campus, que seguem as legislações de inclusão e as diretrizes da Ação TEC NEP, conforme a disponibilização de recursos para aquisição de equipamentos, materiais, tecnologias assistivas e composição de recursos humanos especializados, além da articulação com outros setores para implementação da acessibilidade nos ambiente físicos e atitudinais, promovendo a sensibilização e a cobrança por um ambiente mais igualitário, a fim de proporcionar ao discente com deficiência sua participação ativa, com qualidade e autônoma no ambiente de aprendizagem, reconhecendo-os como sujeitos de sua própria história.

Ter um Núcleo que trabalhe diretamente com a inclusão - apesar da responsabilidade de todo o espaço formal de aprendizagem em promover a inclusão - torna-se fator de importância como elemento que conecta a inclusão com a EPT, trazendo meios de adaptar o espaço formal de aprendizagem no sentido físico, social, pedagógico e atitudinal para o discente com deficiência. Os NAPNEs trabalham com todos os tipos de deficiência, sendo a física, visual, auditiva, intelectual, altas habilidades ou transtornos globais do desenvolvimento, com práticas que variam de acordo com a realidade de cada Instituto (material, físi$\mathrm{ca}$, recursos humanos) e de acordo com cada discente atendido (NASClMENTO; FLORINDO; SILVA, 2013).

Incluir é mais que colocar o discente com deficiência no espaço físico formal de aprendizagem. Exige executar as práticas inclusivas, considerando a existência das diferenças a serem respeitadas e incluídas como parte do espaço que precisa se adaptar, a fim de que possa proporcionar condições para uma formação que não se diferencie pelo aspecto da deficiência, assim como oportunidades de trabalho que considerem a formação do discente e não apenas o atendimento a leis de cotas, por 
exemplo. Segundo Mantoan (2008, p. 10), "o direito à educação esbarra no problema da igualdade de oportunidades, que não se compatibiliza com os ideais inclusivos, pois muitas vezes essa igualdade está a serviço da exclusão e até a justifica", tornando a práxis o caminho para reflexão e transformação da realidade que exclui desde sua origem.

Dessa forma, o desafio dos NAPNEs passa a ser oferecer um AEE de qualidade de acordo com sua estrutura e possibilidades, aplicando as legislações em busca de uma igualdade que passe da teoria, mas que busque na práxis seu poder de mudar a realidade da inclusão de pessoas com deficiência no espaço formal de aprendizagem (COSTA, 2011), sendo setor de fundamental importância como apoio e auxílio para pessoas com deficiência e instrumento de sensibilização e de provocação atitudinal da comunidade escolar.

Ao NAPNE, pertence à atuação no sentido de efetivar os propósitos do TEC NEP, sob o olhar humanístico-sistemático à melhoria do atendimento. É necessário considerar que o atendimento aos alunos com NEE não é puramente o cumprimento de determinações legais e/ ou normativas, mas sim, um conjunto de tomadas de decisões que almejam o exercício da plena cidadania desses alunos e da coletividade (COSTA, 2011, p. 116).

A inclusão como parte da formação humana e profissional contribui para a autonomia e independência do discente com deficiência, preparando-o para uma vida não segregada do mundo do trabalho ou da continuidade de seus estudos, sendo os NAPNEs e todos que trabaIham em prol da inclusão agentes fundamentais para que a práxis aconteça.

\section{Considerações finais}

A inserção de pessoas com deficiência nos processos formativos de educação e sua preparação gradativa para atuar no mundo do trabaIho, por meio da EPT, possui uma legislação que avança no sentido das práticas inclusivas, além da obrigatoriedade de atendimento especializado que possibilita a inclusão e a acessibilidade dos discentes, valorizando e reduzindo as dificuldades enfrentadas, oportunizando de fato e de direito uma profissionalização técnica no processo emancipatório e garantindo sua permanência no mercado de trabalho. 
As práticas de inclusão além de seguirem parâmetros de leis e diretrizes, também são sujeitas à ação humana, para que sejam exploradas e executadas, alinhando aspectos individuais e coletivos do discente com deficiência e do espaço formal de aprendizagem, saindo do discurso de igualdade na teoria para aliá-lo a práticas transformadoras, sendo fundamental a união e articulação da teoria e prática para que se tenha a práxis como criadora e transformadora da realidade.

Dessa forma, as práticas educativas formativas necessitam ser pensadas, refletidas, planejadas e aplicadas no sistema educacional para a transformação da realidade excludente que a sociedade impõe implícita ou explicitamente às pessoas com determinadas deficiências, no seu acesso e permanência no mundo do trabalho. Ao analisar o processo histórico de desenvolvimento da EPT no Brasil, percebeu-se a dualidade estrutural das diferenças no ensino por divisão de classes sociais, seguindo a lógica de interesses das classes dominantes.

Evidencia-se que a atuação dos NAPNEs nos IFs deve garantir o serviço de AEE como objetivo de articulação da inclusão com a EPT em uma ação transformadora e libertadora da realidade excludente, enfrentando as limitações impostas pelas legislações, orçamentos e estrutura organizacional e ainda buscar sensibilizar outros setores e instâncias superiores para se comprometerem coma construção do pensamento crítico contra as desigualdades.

\section{Referências}

ANJOS, I. R. S. Programa TEC NEP: avaliação de uma proposta de Educação Profissional Inclusiva. 2006. 91 f. Dissertação (Mestrado em Educação Especial) - Universidade Federal de São Carlos, Centro de Educação e Ciências Humanas, São Carlos, 2006. Disponível em: https://repositorio.ufscar.br/bitstream/handle/ufscar/2949/1171. pdf? sequence=1\&isAllowed=y. Acesso em: 10 jun. 2019.

BRASIL. Constituição da República Federativa do Brasil de 1988. Brasília, DF: Presidência da República, 1988. Disponível em: http://www. planalto.gov.br/ccivil_03/Constituicao/Constituicao.htm. Acesso em: 15 maio 2019.

BRASIL. Decreto no 7.611, de 17 de novembro de 2011. Dispõe sobre a educação especial, o atendimento educacional especializado e dá 
outras providências. Diário Oficial da União: Brasília, DF, 18 nov. 2011. Disponível em: http://www.planalto.gov.br/ccivil_03/_ato20112014/2011/decreto/d7611.htm . Acesso em: 04 mai. 2019.

BRASIL. Lei no 13.146, de 6 de julho de 2015. Institui a Lei Brasileira de Inclusão da Pessoa com Deficiência (Estatuto da Pessoa $132 \mathrm{com}$ Deficiência). Diário Oficial da União: Brasília, DF, 7 jul. 2011. Disponível em: http://www.planalto.gov.br/ccivil_03/_ato2015-2018/2015/lei/ 113146.htm . Acesso em: 05 mai. 2019.

BRASIL. Lei № 9.394, de 20 de dezembro de 1996. Estabelece as diretrizes e bases da educação nacional. Diário Oficial da União: Brasília, DF, 23 dez. 1996. Disponível em: http://www.planalto.gov.br/ccivil_03/Leis/ L9394.htm Acesso em: 05 maio 2020.

BRASIL. Ministério da Educação. Inclusão. Revista da Educação Especial. Política Nacional de Educação Especial na Perspectiva da Educação Inclusiva. Secretaria de Educação Especial, v. 04. n 05. Brasília: SEESP, 2008b. Disponível: http://portal.mec.gov.br/seesp/arquivos/pdf/ revinclusao5.pdf. Acesso em 04 mai. 2019.

BRASIL. Ministério da Educação. Política Nacional de Educação Especial na Perspectiva da Educação Inclusiva. Brasília, 2008a. Disponível em: http://portal.mec.gov.br/index.php?option=com_ docman\&view $=$ download\&alias $=16690$-politica-nacional-deeducacao-especial-na-perspectiva-da-educacao-inclusiva05122014\&ltemid=30192. Acesso em 28 abr. 2019.

BRASIL. Ministério da Educação. Secretaria de Educação Profissional e Tecnológica. Portaria n 29, de 25 de fevereiro de 2010. Disciplina a forma de operacionalização da Ação Educação, Tecnologia e Profissionalização para Pessoas com Necessidades Educacionais Especiais - TEC NEP. Brasília: DF, 2010.

CARNEIRO, M. A. LDB fácil: Leitura crítico-compreensiva, artigo a artigo. 18. Ed. Petrópolis, RJ: Vozes, 2011.

COSTA, G. M. A. D. Núcleo de Atendimento aos Alunos com Necessidades Educacionais Especiais (NAPNE): ações para inclusão em uma instituição de ensino profissional do Estado de Pernambuco. 2011, 136 f.: Dissertação (mestrado em Educação Brasileira) Universidade Federal de Alagoas, Maceió, 2011. Disponível em: 
http://www.repositorio.ufal.br/bitstream/riufal/1513/1/Nucleo\%20 de\%20atendimento\%20aos\%20alunos\%20com\%20necessidades $\% 20$ educacionais $\% 20$ especiais $\% 20 \% 28$ NAPNE $\% 2$ 29 20 - $\% 20$ a\%C3\%A 7\%C3\%B 5es\%20para\%20a\%20inclus\%C3\%A3o\%20 em $\% 20$ uma $\% 20$ institui $\%$ C3\%A7\%C3\%A3o\%20de\%20ensino $\% 20$ profissional\%20do\%20Estado\%20de\%20Pernambuco.pdf. Acesso em 15 jun. 2019.

CUNHA, A. M. S. Educação profissional e inclusão de alunos com deficiência:um estudo no Colégio Universitário/UFMA. 228f. Dissertação (Mestrado em Educação) - Universidade Federal no Maranhão, Centro de Ciências Sociais, São Luís, 2011. Disponível em: https://tedebc.ufma. br/jspui/bitstream/tede/200/1/Dissertacao\%20Angelica\%20Moura\%20 Siqueira\%20Cunha.pdf. Acesso em 25 maio 2019.

FREIRE, P. Educação como prática da liberdade. 14. ed. Rio de Janeiro: Paz e Terra, 2011.

FREIRE, P. O sentido da avaliação na prática de base. In: QUEIROZ, J. J. A educação popular nas comunidades eclesiais de base. São Paulo: Paulinas, 1985. p. 97-101.

FREIRE, P. Pedagogia da autonomia: saberes necessários à prática educativa. 5 ed. Rio de Janeiro: Paz e Terra, 1996.

FREIRE, P. Pedagogia do oprimido. 32. ed. Rio de Janeiro: Paz e Terra, 2002.

FREIRE, P. Política e educação. 5. ed. São Paulo: Cortez, 2001.

JANNUZZI, G. M. A educação do deficiente no Brasil: dos primórdios ao início do século XXI. Campinas: Autores Associados, 2004.

MANTOAN, M. T. E. (Org.). O desafio das diferenças nas escolas. Petrópolis: Vozes, 2008.

MANTOAN, M. T. E. Inclusão Escolar: o que é? por quê? como fazer? São Paulo: Moderna, 2003.

NASCIMENTO, F. C.; BUGARIM, M.C.; MARTINS, I.C.; MARTINS, A. A ação TEC NEP - Tecnologia, Educação, Cidadania e Profissionalização para Pessoas com Necessidades Específicas como ferramenta de inclusão nas Instituições Federais de Educação Profissional e Tecnológica. Revista Cientifica Internacional Inter Science Place. n. 18 de jul./set. 2011. 
Disponível em: http://www.interscienceplace.org/isp/index.php/isp/ article/view/175/173. Acesso em: 8 jun. 2019.

NASCIMENTO, F. C.; FARIA, R. A. Questão da inclusão na Rede Federal de Educação Profissional, Científica e Tecnológica, a partir da Ação TEC NEP. In: NASCIMENTO, F. C.; FLORINDO, G. M. F.; SILVA, N. S. (org.). Educação profissional e tecnológica inclusiva: um caminho em construção. Brasília: Instituto Federal de Educação, Ciência e Tecnologia de Brasília, 2013. p.13-23. Disponível: http://revistaeixo.ifb.edu.br/index.php/ editoraifb/article/viewFile/185/86. Acesso em: 03 mai. 2019.

NASCIMENTO, F. C.; FLORINDO, G. M. F.; SILVA, N. S. (org.). Educação profissional e tecnológica inclusiva: um caminho em construção. Brasília: Instituto Federal de Educação, Ciência e Tecnologia de Brasília, 2013. Disponível: http://revistaeixo.ifb.edu.br/index.php/editoraifb/ article/viewFile/185/86. Acesso em: 03 mai. 2019.

QUEIROZ, E. M. O. Cotas na UFG e desempenho acadêmico: Tensões e contradições. In: MIRANDA, M. G. de (Org). Educação e Desigualdades sociais. Campinas, SP: Mercado de Letras, 2016.

SASSAKI, R. K. Inclusão: Construindo Um a Sociedade Para Todos. 3. ed. Rio de Janeiro: WVA, 1999.

UNESCO. Declaração mundial sobre Educação para Todos: satisfação das necessidades básicas de aprendizagem, Jomtien, 1990. Unesco, 1998b. Disponível em: https://unesdoc.unesco.org/ark:/48223/ pf0000086291_por. Acesso em: 13 jan. 2019.

UNESCO. Declaração sobre Princípios, Políticas e Práticas na Área das Necessidades Educativas Especiais. Salamanca, 1994. Brasília: UNESCO, 1998. Disponível em: http://portal.mec.gov.br/seesp/arquivos/ pdf/salamanca.pdf. Acesso em 06 mai. 2019.

VÁSQUEZ, A. S. Filosofia e Circunstâncias. Rio de Janeiro. Civilização Brasileira, 2002.

VÁZQUEZ, A.S. Filosofia da Práxis. Rio de Janeiro: Paz e Terra, 1977.

Recebido em: Junho/2019

Aceito em: Dezembro/2019 